\title{
Producción de Hortalizas en Ambientes Protegidos: Medios de Siembra y Contenedores ${ }^{1}$
}

\author{
Bielinski M. Santos and Henner A. Obregon-Olivas²
}

\section{Producción en suelos: Desinfección, mejoramiento, cultivos de cobertura, acolchados (mulches)}

La producción de cultivos en suelos es el método más usado alrededor del mundo. Sin embargo, al producir en suelos se presentan problemas de plagas y enfermedades afectando la calidad y rendimiento de los diferentes cultivos.

\section{Desinfección del suelo}

La desinfección del suelo es un proceso que consiste en eliminar la mayor cantidad de plagas y enfermedades que sean perjudiciales para las plantas. Es una práctica que se emplea en horticultura, sobre todo en estructuras protegidas. A continuación, mencionaremos algunos métodos de desinfección de suelos.

Agua caliente. El uso de agua caliente es uno de los métodos más utilizados para realizar la desinfección. Este consiste en la aplicación de agua caliente a una temperatura de 80 a $100^{\circ} \mathrm{C}$. Sin embargo, el efecto del agua caliente puede ser negativo ya que si se aplica a demasiada profundidad puede destruir las bacterias nitrificantes del suelo. La desinfección con agua caliente es un método altamente efectivo, aunque su principal inconveniente es su alto costo.
Solarización. La solarización es una técnica para desinfectar el suelo. Se realiza cubriendo el terreno con una lámina plástica de polietileno durante un periodo de tiempo comprendido entre 4 y 8 semanas. Es importante efectuar los riegos por debajo del plástico durante este tiempo. El objetivo es alcanzar altas temperaturas que destruyan las plagas y enfermedades existentes en el suelo. La solarización se realiza generalmente en los meses en que la temperatura ambiental es más alta.

Desinfección del suelo con productos químicos. Esta técnica está basada en el empleo de distintos productos químicos para lograr la desinfección del suelo.

\section{Mejoramiento del suelo}

El suelo puede ser pobre en nutrientes por diferentes causas. Por ejemplo, los suelos predominantemente arenosos son tan porosos que no pueden retener la humedad ni los nutrientes requeridos por periodos prolongados de tiempo. En contraste, existen suelos ricos en nutrientes, pero mal aireados o con pobre drenaje que los organismos del suelo no son capaces de poner los nutrientes a disposición de las plantas. En ambos casos, se puede mejorar la vida del suelo a través de diferentes prácticas culturales.

El uso de materia orgánica para mejorar los suelos y agregar nutrientes necesarios para el crecimiento de las plantas es importante para el éxito de los cultivos. En general, la

1. Este documento, HS1216, es uno de una serie de publicaciones del Horticultural Sciences, Servicio de Extensión Cooperativa de la Florida, Instituto de Alimentos y Ciencias Agrícolas, Universidad de la Florida. (UF/IFAS). Fecha de primera publicación: marzo 2013. Visite nuestro sitio web EDIS en http:// edis.ifas.ufl.edu.

2. Bielinski M. Santos, associate professor and horticultural research associate, Gulf Coast Research and Education Center, University of Florida Institute of Food and Agricultural Sciences, Wimauma, FL 33598; and Henner A. Obregon-Olivas, director, Agropecuaria San Antonio, Tecolostote, Nicaragua. 
materia orgánica está compuesta por restos de plantas y animales. Los compuestos orgánicos más comunes que se aplican al suelo son el estiércol de aves y animales, abonos verdes, cultivos de cobertura y compost. Entre los beneficios de añadir materia orgánica al suelo se encuentran:

1. Mejora la labranza, la condición y la estructura del suelo, proporcionando una mejor aireación y temperatura.

2. Mantiene los organismos benéficos del suelo.

3. Mejora la capacidad del suelo para retener agua y nutrientes.

4. Mantiene un suministro constante de nutrientes para las plantas.

5. Pueden contribuir, en cierta medida, al control biológico de las plagas del suelo.

6. Fuente de energía de menor costo que algunos fertilizantes químicos.

Para cultivos sembrados directamente en el suelo, en estructuras protegidas, se recomienda construir camas elevadas de $\mathrm{X} \mathrm{cm}$ de altura cubiertas con plástico (las líneas de riego por goteo deben estar colocadas previamente en las camas antes de ser cubiertas por el plástico).

La preparación del suelo consiste en mezclar estiércol de gallina o de pollos (conocidos como gallinaza o pollinaza) o compost, con el suelo de las camas. El objetivo es crear un suelo suelto y aireado, que fomente el desarrollo de un sistema radicular sano. El establecimiento de camas elevadas evita también la compactación, garantizando que las personas que laboran en el cultivo no estén demasiado cerca de las plantas. Muchos productores han logrado mejorar el suelo al incorporar estiércol como la gallinaza, pollinaza, porquinaza o el compost de estiércol bovino. La mezcla de abonos verdes con estiércol también es efectiva.

Cultivos de cobertura. Los cultivos de cobertura, son sembradíos utilizados fundamentalmente para mejorar la calidad del suelo, la fertilidad, el uso del agua, control de malezas, plagas y enfermedades. Aunque los cultivos de cobertura pueden pertenecer a cualquier familia de plantas, la mayoría son leguminosas que a menudo son incorporadas al suelo antes de llegar a su madurez con el fin de mejorar la fertilidad y calidad del suelo.

Abonos verdes. Los abonos verdes son derivados de las plantas; pueden ser plantas enteras o cultivos de cobertura. Las plantas tienen un átomo de carbono superior a la proporción de nitrógeno del estiércol de la mayoría de animales y por lo tanto son excelentes para mejorar la estructura del suelo. Los materiales leñosos como la paja, aserrín, virutas de madera, deben ir acompañados por una fuente de nitrógeno, tales como el estiércol de animales o cultivos de leguminosas.

"Mulching" o acolchado de suelos. El "mulching” se traduce habitualmente como acolchado. Es una técnica muy antigua que consiste en colocar materiales como paja (pasto picado), madera triturada, aserrín, cascarilla de arroz, plástico o papel, para cubrir el suelo. El uso de "mulch" o acolchado de suelo, surge como una alternativa tecnológica para mejorar la producción de hortalizas, porque además de intensificar la producción (adelanto de cosecha y mejoramiento del rendimiento y la calidad del fruto), permite un ahorro significativo de agua, y aumenta la eficiencia del uso de recursos como la mano de obra. Los acolchados tienen como finalidad:

1. Reducir la evaporación, lo que se traduce en una mayor eficiencia en el uso del agua de riego y también menos gastos en fertilizantes (al reducir la lixiviación, se evita la pérdida de nutrientes).

2.Evitar la aparición y proliferación de malezas (grandes competidoras de agua y nutrientes del suelo).

3. Mejorar la estructura del suelo y el desarrollo radicular. Protege la estructura del suelo, manteniendo el suelo mullido. En estas condiciones las plantas desarrollan más su sistema radical (superficial y lateral). El aumento de raíces asegura a la planta una mayor extracción de agua y sales minerales, lo que conduce a mayores rendimientos.

4.Favorecer la fertilidad del suelo. El aumento de la temperatura y humedad del suelo provocado por el uso de algunos tipos de acolchado, favorece la mineralización del suelo, lo que lleva a una mayor disponibilidad de nitrógeno para las plantas.

5. Reducir la erosión causada por la lluvia y el viento.

6. Mantener la temperatura de las raíces.

7. Impedir el contacto de los frutos con el suelo para disminuir la incidencia de plagas y enfermedades.

El acolchado usa distintos materiales que pueden ser orgánicos e inorgánicos. La ventaja de los materiales inorgánicos es que se mantienen en perfectas condiciones durante largos periodos de tiempo. Sin embargo, los 
materiales orgánicos enriquecen el terreno a medida que se descomponen, inyectando nutrientes al suelo.

\section{Acolchados orgánicos (cortezas, pajas, virutas de} madera). Existen varias clases de acolchados orgánicos como: corteza de pino, virutas de madera, residuos de poda triturados, hojas, pajas, etc. Las cortezas y virutas de madera ofrecen una descomposición más lenta, lo que aumenta su durabilidad.

Acolchados inorgánicos (plásticos y gravas). Entre los acolchados inorgánicos se pueden mencionar: la grava, arena, tierra volcánica, carbón vegetal, plásticos, agro textiles, etc. Estos ayudan a mantener el terreno a salvo de las inclemencias del tiempo, mantienen la humedad y fomentan el desarrollo de plantas y frutos. Los distintos tipos de gravas, gravillas, piedras y rocas ofrecen protección y, además, muchas posibilidades decorativas para el diseño de jardines. El polietileno, por su bajo costo, es el material más utilizado en acolchado de suelos a nivel mundial. Además, es de fácil uso ya que su instalación puede ser mecánica (Foto 1).

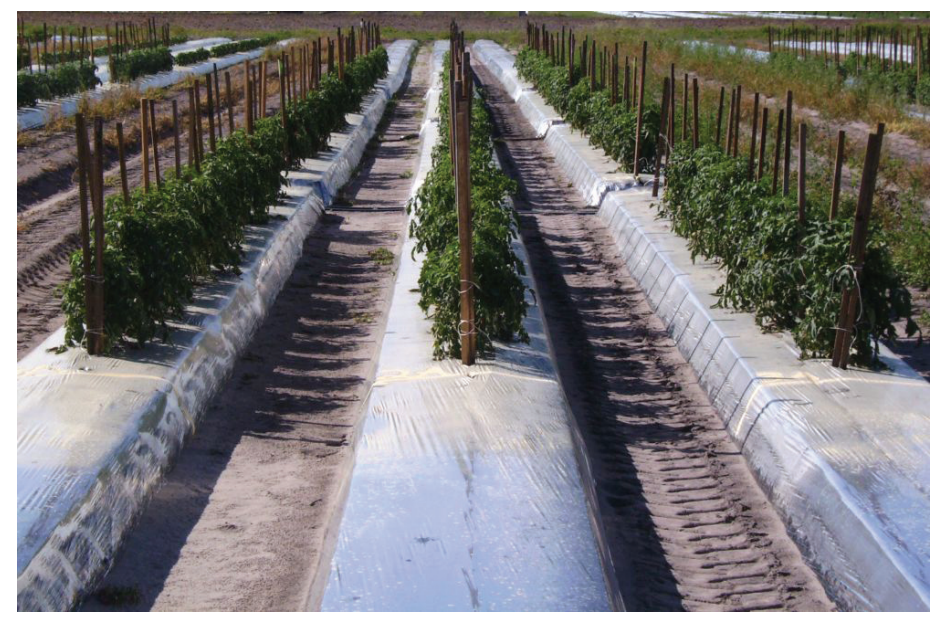

Figura 1. Acolchado plástico del suelo para la producción de tomates Credits: B. M. Santos

\section{Cultivos sin suelo}

La producción de hortalizas en diferentes sistemas de cultivos "sin suelo" en combinación con estructuras protegidas (invernaderos, casas malla, macrotúneles) constituye, aparte de la rentabilidad del cultivo, una tecnología que permite la obtención de producciones de excelente calidad y altos rendimientos por unidad de área, asegurando un uso más eficiente de agua y nutrientes. Los sistemas de cultivos sin suelo se pueden clasificar en tres grandes grupos dependiendo del medio en el que se desarrollen las raíces: a) sustratos sólidos, b) hidropónicos puros y c) aeropónicos.
Cultivos en sustratos: Las raíces de las plantas crecen y se desarrollan en sustratos inertes donde se aplican soluciones nutritivas.

Cultivos en agua o hidropónicos puros: En este sistema las raíces de las plantas se mantienen en contacto con una lámina muy delgada de agua que contiene los nutrientes (conocido como sistema de raíz flotante o sistema "NFT" [Nutrient Film Technique]).

Cultivos en aire o aeropónicos: Las raíces crecen en el aire y son asperjadas periódicamente con una solución nutritiva.

Tipos de sustratos. Sustrato es todo material sólido que puede ser usado como sustituto del suelo natural y que sirve como el medio donde va a desarrollarse la raíz del cultivo. El principio básico de esta técnica es que el sustrato ayuda a darle soporte a la planta, protege la raíz de la luz y retiene la solución nutritiva así como la humedad para que la planta pueda absorber nutrientes. En teoría, los sustratos funcionan con todas las especies y variedades de hortalizas debido a su similitud con el cultivo en suelo. Sin embargo, a nivel comercial, se recomienda su uso para cultivos como el tomate, sandía, melón, pepino, uva, apio, frijol, fresa, chiles, pimientos, maíz, papa y cebolla.

El éxito en la producción de hortalizas cultivadas en invernaderos, casas malla y macro-túneles depende en gran parte de las propiedades químicas (capacidad de intercambio catiónico, solubilidad) y físicas (porosidad, densidad, estructura, granulometría, capacidad de retención de agua) de los sustratos, del tipo de cultivo, la frecuencia de riego y las condiciones climáticas. Los sustratos pueden usarse solos o en mezclas. Otros parámetros a considerar incluyen costos, disponibilidad, consistencia entre lotes y estabilidad del sustrato a través del tiempo. La selección de los componentes correctos del sustrato es fundamental para una producción exitosa de hortalizas.

\section{Sustratos orgánicos}

Turba de musgo ("peat moss"). La turba es un componente muy común para las mezclas en estructuras protegidas (Foto 2). La turba es normalmente incluida en la mezcla para aumentar la capacidad de retención de agua o para disminuir el peso. La turba de musgo es el sustrato más utilizado en la horticultura y se deriva principalmente del musgo Sphagnum, es normalmente de color marrón claro pardo, ligero $\left(3 \mathrm{~kg} / \mathrm{m}^{3}\right)$, alta capacidad de retención de humedad y muy ácido ( $\mathrm{pH} 3.8$ a 4.3). Un problema importante con la turba es su hidratación. La turba es 
intrínsecamente hidrofóbica (repele el agua). Para hacer frente a esta situación, algunos proveedores ofrecen un producto con un agente humectante ya incluidos. Antes de utilizar la turba, debe realizar una sencilla prueba para ver lo difícil que el producto será para mojar. Si el producto no incluye un agente humectante, puede incorporar uno o utilice agua caliente si es posible, para acelerar el proceso de hidratación. La turba se vende típicamente en fardos prensados que se expanden desde $50 \%$ hasta $100 \%$ cuando están hidratadas. La mayoría de las recetas de turba requieren mezclarse en base al volumen (por ejemplo, el 50\% de turba, $50 \%$ de perlita).

Fibra de coco. La fibra de coco es un sustrato orgánico relativamente nuevo, utilizado principalmente en la industria de la agricultura protegida que se está convirtiendo rápidamente en un sustrato muy popular. La fibra de coco es considerada como un posible sustituto de la turba de musgo. La materia prima de la fibra se deriva de la cáscara del fruto de coco (Cocus nucifera). Este material procede de varios países, como Sri Lanka, India, Filipinas, México y Centroamérica. Debido a que la fibra de coco contiene más lignina y menos celulosa que la turba, es más resistente a la descomposición microbiana y, por lo tanto, puede encogerse menos. La fibra de coco es más fácil humedecerla después del secado que la turba. Es un excelente sustrato, por su capacidad de retener humedad y ofrece grandes ventajas para la mezcla con otros sustratos.

Madera de corteza de pino. La corteza de pino es el componente principal ( $80 \%$ a $100 \%$ en volumen) en la mayoría de mezclas en contenedores. Durante muchos años, la corteza era vista como desecho del bosque. En la actualidad, la disponibilidad de este material para el uso en contenedores es limitada en algunos mercados debido a la demanda para otros usos (por ejemplo, material para jardines, combustible) y la reducción en la producción de madera de pino (Foto 2). La corteza de pino es preferible a la madera de corteza dura, ya que resiste la descomposición y contiene menos ácidos orgánicos. La corteza de pino suele es removida de los árboles, molida y luego clasificada según su tamaño. La corteza se describe como fresca, vieja o compostada. Muchos productores utilizan la corteza fresca. El envejecimiento es el proceso más barato, pero la corteza vieja tiene menos humus que la corteza compostada. El compostaje de la corteza normalmente tarda de 5 a 7 semanas.

Madera de corteza dura. Las propiedades químicas de la corteza de madera dura son significativamente diferentes a la corteza de pino. La corteza de madera dura generalmente

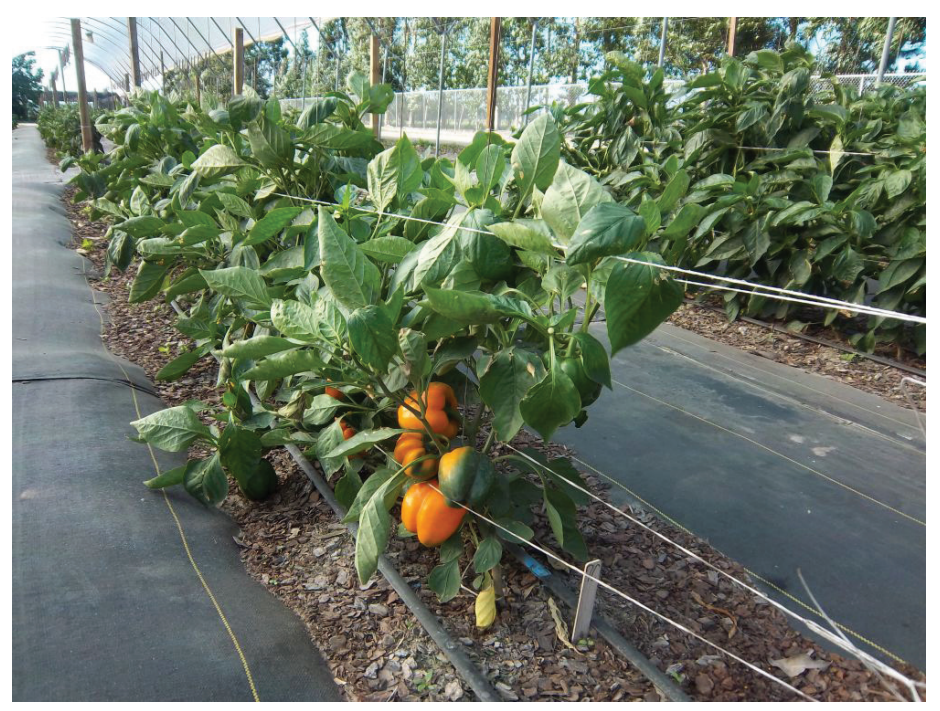

Figura 2. Pimientos producidos con corteza de pino en un sistema de trincheras

Credits: B. M. Santos

contiene compuestos tóxicos y, por esta razón, debe ser compostada antes de su uso.

Compost. El compost es la descomposición microbiana de los residuos orgánicos bajo condiciones controladas. Una gran variedad de productos compostados o abonos de origen animal y/o vegetal están disponibles en el mercado. Las desventajas del uso del compost incluyen posibles concentraciones elevadas de sales, variabilidad en el tamaño de partículas, presencia de semillas de malezas y la disponibilidad del mismo. Las ventajas del uso del compost incluyen la aportación de nutrientes y el mejoramiento de las propiedades físicas en los sustratos. En algunas áreas, los productos de compostaje son de bajo costo.

Cascarilla de arroz. La cascarilla de arroz está disponibles en diferentes formas utilizando nombres como fresca, escaldada, carbonizada y compostada (convertida en abono). Debido a sus propiedades físicas, la cascarilla de arroz vaporizada y fresca puede ser usada como un sustituto de la perlita en muchas mezclas. La cascarilla escaldada (vaporizada) es preferible, ya que cualquier maleza o semilla de arroz muere durante el proceso de la presión del vapor. La cascarilla fresca tiene un $\mathrm{pH}$ cercano al neutro y es de peso ligero (densidad aparente 21 a $33 \mathrm{~kg} / \mathrm{m}^{3}$ ) lo cual es útil para mejorar el drenaje y la ventilación.

Aserrín y virutas de madera. En general, los productos de madera o aserrín no se recomiendan como sustrato. La proporción de carbono-nitrógeno es extremadamente alta, por lo que requieren cantidades adecuadas de nitrógeno y de compostaje para evitar efectos negativos en el crecimiento de las plantas. 


\section{Sustratos inorgánicos}

Perlita. La perlita es comúnmente usada como un componente de los sustratos en la agricultura protegida (Foto 3). Se produce por calentamiento de la roca ígnea a temperaturas cerca de $1000^{\circ} \mathrm{C}$. La perlita se diferencia de la vermiculita en que el producto final es una célula "cerrada" que no absorbe o retiene el agua. Por esta razón, generalmente se incluye en una mezcla para mejorar el drenaje o aumentar el porcentaje de aireación. La perlita es ligera ( 6 a $8 \mathrm{~kg} / \mathrm{m}^{3}$ ), químicamente inerte, $\mathrm{pH}$ neutro, estéril y sin olor.

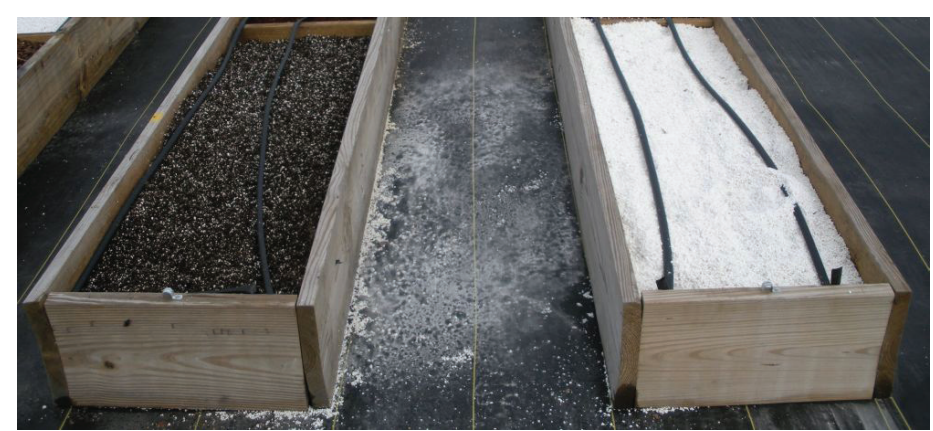

Figura 3. Cajas de madera llenas de sustrato comercial con musgo y perlita (izquierda) y perlita (derecha)

Credits: B. M. Santos

Vermiculita. En cierto modo la vermiculita es similar a la perlita ya que ambas se originan como minerales extraídos y luego se calientan para producir el producto final. La perlita generalmente se incluye en una mezcla para mejorar el drenaje pero no aumenta la retención de nutrientes. Por el contrario, la vermiculita con su estructura de placa mantiene grandes cantidades de agua y cargas positivas de nutrientes como potasio, magnesio y calcio. La vermiculita es estéril y de peso ligero $\left(21\right.$ a $\left.33 \mathrm{~kg} / \mathrm{m}^{3}\right)$. El $\mathrm{pH}$ de la vermiculita varía dependiendo de donde se extrae. La vermiculita se utiliza ampliamente en la industria de invernaderos como componente de la mezcla del sustrato.

Arena. La arena es un sustrato común y se utiliza ocasionalmente para mezclas en viveros e invernaderos. La arena es típicamente seleccionada como un componente de sustrato para mejorar el drenaje o para prevenir que los contenedores se vuelquen en los invernaderos. Sin embargo, evite el uso de arenas calcáreas o arenas del mar que son obviamente de solución salina. La arena rara vez ocupa más del $10 \%$ del volumen en una mezcla, debido al peso (densidad aparente de 327 a $409 \mathrm{~kg} / \mathrm{m}^{3}$ ).

Lana de roca. La lana de roca ha sido ampliamente utilizada en Europa y recientemente en el mercado de invernaderos de Estados Unidos. Al igual que la perlita y vermiculita, se origina de un mineral natural (silicato de aluminio con algo de calcio y magnesio) que se calienta a $1500^{\circ} \mathrm{C}$ para formar fibras que se utilizan para hacer los bloques o cubos como un producto terminado. Los bloques de lana de roca son muy utilizados por los productores de hortalizas en invernaderos. La lana de roca normalmente tiene un $\mathrm{pH}$ alcalino, es estéril y químicamente inerte.

Otros sustratos inorgánicos. Algunos materiales que no se utilizan comúnmente incluyen: piedra pómez, arcilla calcinada, arena de río, arena de cantera, gravilla, grava, residuos de ladrillo, etc.

Mezclas típicas en estructuras protegidas. La mayoría de productores en estructuras protegidas usan sustratos esterilizados. Los principales componentes en una mezcla son la turba, vermiculita, perlita, corteza de pino, turba y arena. Muchos productores utilizan $80 \%$ de corteza de pino, un $10 \%$ de turba y $10 \%$ de arena. Otros combinan cascarilla de arroz con gallinaza, pollinaza, o compost. Un ejemplo de ello es $50 \%$ de cascarilla de arroz, $25 \%$ pollinaza, y $25 \%$ compost.

\section{Tipos de contenedores}

Los contenedores o recipientes (sacos, macetas, canaletas, bolsas, etc.), se encargan de aislar, dar forma y condicionar en gran medida las propiedades del contenido, preservándolo de la luz, de los agentes contaminantes y evitar la pérdida de agua por evaporación, entre otros. Los contenedores son fabricados con materiales ligeros, generalmente plásticos (polietileno, polipropileno) rígidos o flexibles, accesibles en precio y de fácil manejo y reposición. Para garantizar un medio ideal, los contenedores deben estar libres de malezas y enfermedades y deben tener suficiente peso para impedir que se vuelquen. En la actualidad los contenedores más utilizados son bandejas plásticas, macetas, bolsas plásticas, sacos de polietileno, canaletas de madera o plástico, cajas plásticas y contenedores verticales (Fotos 4 a 7).

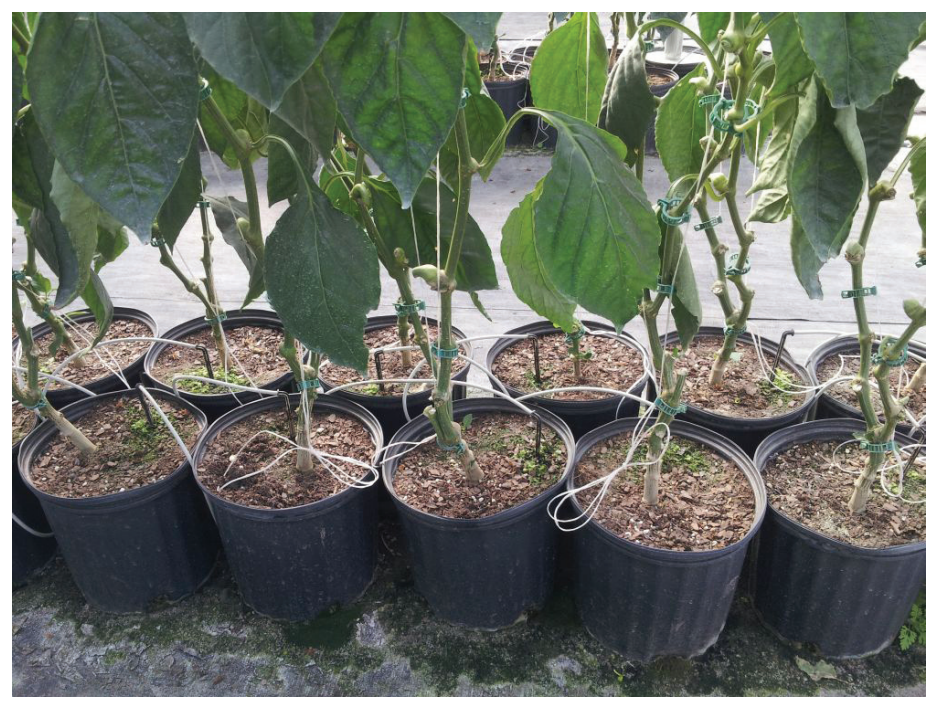

Figura 4. Macetas plásticas utilizadas como contenedores en pimiento Credits: B. M. Santos 


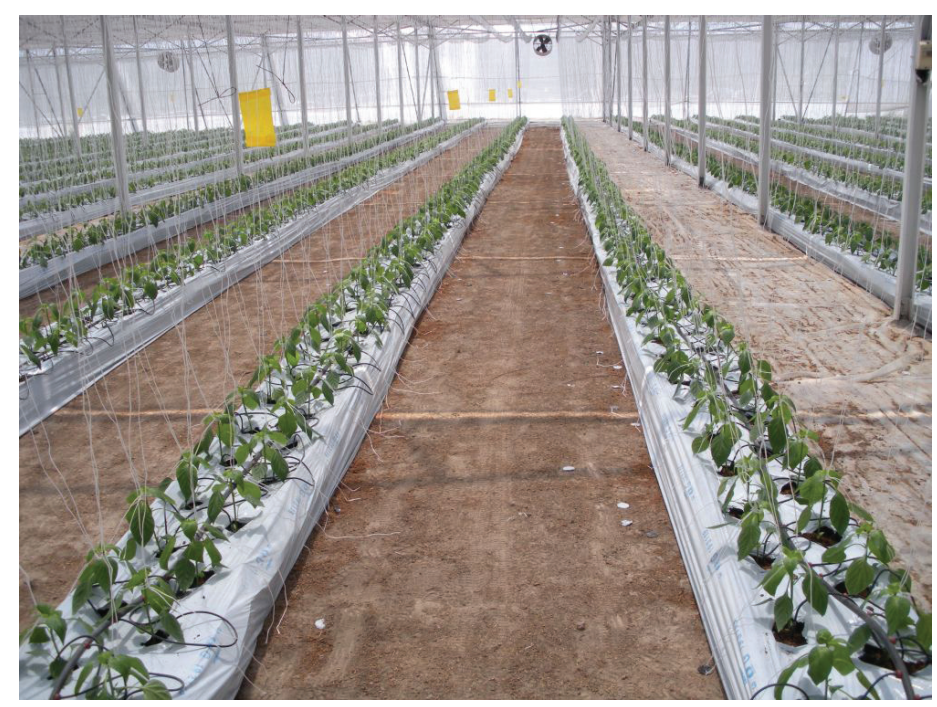

Figura 5. Bolsas planas utilizadas como contenedores en tomate Credits: B. M. Santos

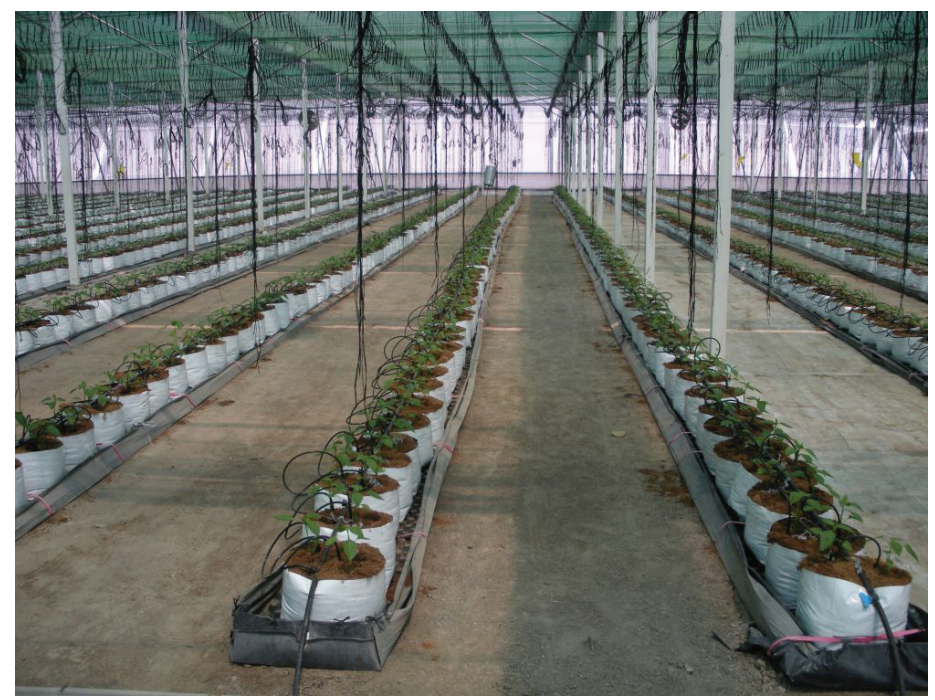

Figura 6. Bolsas plásticas para viveros utilizadas como contenedores en tomate

Credits: B. M. Santos

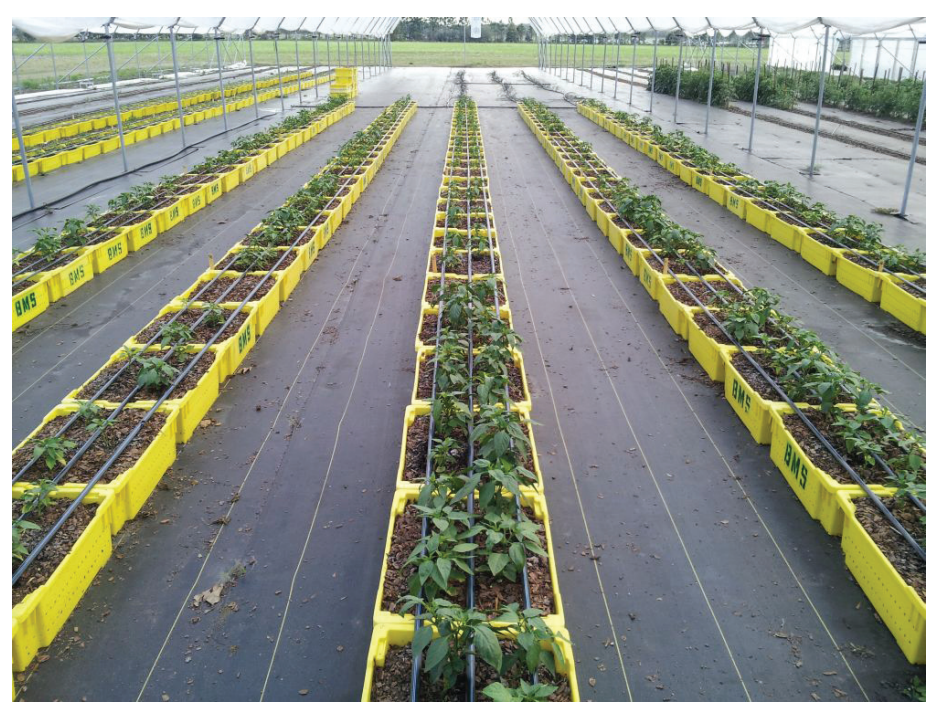

Figura 7. Cajas plásticas utilizadas como contenedores Credits: B. M. Santos 